\title{
CONFERENCIA
}

\section{HABITOS ORALES: Apropiados y Deletereos}

\author{
Pia Villanueva ${ }^{10}$ \\ Profesora Asociada Facultad de Odontología Universidad de Chile \\ Facultad de Medicina Universidad de Chile. \\ Fonoaudióloga, Especialista en Motricidad Orofacial (CEFAC) \\ MAgister en Ciencias Odontológicas \\ Doctorada (c) en Psicología y Ciencias Cognitivas
}

Considerando nuestra realidad nacional y la falta de pautas que orienten la incorporación de hábitos orales favorables, dedicado a los padres como a los profesionales que trabajan con niños. El año recién pasado se presentó a nuestra comunidad científica, una herramienta de prevención de malos hábitos orales, llamado PIAHO Protocolo de Incorporación Apropiada de Hábitos Orales, mediante la comparación de los diagnósticos de resistencia nasal obtenidos de la prueba subjetiva PeNaF con los diagnósticos obtenidos por la prueba objetiva de rinomanometría.

Se estudiaron las relaciones entre la incorporación de consistencias, herramientas y elección de posturas durante la alimentación y los diferentes tipos de deglución. En una muestra pareada por edad, genero y estadio de dentición. Esta nueva estrategia y plan de acción para una oportuna incorporación de consistencias y utensilios de alimentación, también enfocado en una correcta higiene nasal, se estima permitirá contribuir a la prevención de alteraciones miofuncionales, y evitar la instauración de malos hábitos orales. Se presentarán las apreciaciones de la comunidad frente a distintas conductas de padres y cuidadores, que segun nuestro criterio profesional, son calificados en hábitos orales apropiados o deletéreos

10. Fonoaudióloga, Especialista en Motricidad Orofacial (CEFAC), Magister en Ciencias Odontológicas, Doctorada (c) en Psicología y Ciencias Cognitivas, Profesora Asociada Facultad de Odontología Universidad de Chile Facultad de Medicina Universidad de Chile. 